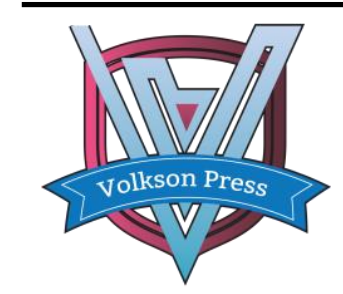

Contents List available at VOLKSON PRESS

Engineering \& Technology Innovations (ETI)

DOI : http://doi.org/10.26480/iceti.01.2017.139.141

\title{
ECOLOGICAL ASSESSMENT OF CARRYING CAPACITY OF SEVENTY-TWO PATHS TOURISM PLANNING OF SOUTHERN CHINA
}

\author{
Wei Huang', Yuanjun Huang', Ruwen Liang', Daobo WANG'+, Zhilian Fan ${ }^{1 \dagger}$
}

(1. College of Agriculture, Guangxi University/Research Center of Beibu Gulf Marine Culture, Guangxi, 530004, China; 2. College of Resources and Environment, Qinzhou University, Guangxi, 535099, China)

+ Corresponding author: 363583837@qq.com (DW, Ph.D., Prof.), 464259744@qq.com(ZF, Associate Prof.)

This is an open access article distributed under the Creative Commons Attribution License, which permits unrestricted use, distribution, and reproduction in anv medium, provided the oriainal work is properlv cited

\section{ARTICLE DETAILS}

\section{Article History:}

Received 02 october 2017

Accepted 06 october 2017

Available online 11 october 2017

Keywords:

Beibu Gulf; Ecological Carrying Capacity; Uninhabited Islands Group; Tourism Ecological Footprint; Ecotourism

\section{ABSTRACT}

Taken the Seventy-two Paths in Qinzhou as example, the ecological carrying capacity of the tourism planning of uninhabited islands group was studied in the Northern Gulf of Southern China. Based on ecological footprint model, uninhabited islands consumption model of tourism ecological footprint was the established, from the view of the restaurant, accommodation, traffic, entertainment, sightseeing and shopping. And then, the ecological deficit was calculated through the evaluation of the tourism carrying capacity of uninhabited islands. The results showed that, (1) according to the planning, $\mathbf{5 3 1 9 . 0 3}$ ha of total ecological footprint was required to meet the needs of the expected tourists; (2) to provide ecological footprint planning area are 788.56ha, the ecological deficit is $4530.47 \mathrm{ha}$, and the ecological deficit is 5.75 times to provided by the local ecological footprint. It cannot bear the demands of ecological footprint, and a large number of external inputs were needed to maintain the ecological equilibrium Seventy-two Paths. Consumption model of tourism ecological footprint of uninhabited island could provide some reference to the development of uninhabited island in Southern China. At the same time, the model could enrich the theory and application of ecological carrying capacity.

\section{INTRODUCTION}

Ecological footprint model was proposed by the ecological economist William of Canadian in 1992 firstly ${ }^{[1]}$. Quantitative method of assessment of the sustainable development of ecology was to improve by Mathis, which land as a unit of measure ${ }^{22}$. The concept of touristic ecological footprint(TEF) was first proposed by Hunter in $2002^{[3]}$. It refers to all necessary bio productive land was converted by a variety of resource consumption and waste generated well absorb, which related to tourism activities, within a certain time and space.

There are many studies on the ecological carrying capacity by TEF. Su et al (2015) ${ }^{[4]}$ thought that the development of tourism in the Meizhou Island was unsustainable, which would lead to adverse impacts on adjacent environments. To ensure sustainable development of tourism, more short-distance travel and low-carbon travel should be encouraged, and effective measures must be taken to reduce energy use as well. Yuan et al (2015) ${ }^{[5]}$ deemed that TEF in Lushunkou District of Dalian was in surplus state, and the coastal tourism resources in the region still have great potential for development. Yang and $\mathrm{Xu}(2016)^{[6]}$ considered that the Zhangjiajie tourism ecological footprint always is on the rise, Zhangjiajie tourism development is still in an unsustainable state, ecological defi cit is on the rise as a whole. $\mathrm{Li}$ and Nie (2016) ${ }^{[7]}$ maintained that the total tourism ecological footprint, the total tourism carrying capacity and the total tourism deficit showed a slow growth pace. For the ecological footprint index and ecological tension index, it reflects the development of forest parks of Guizhou in an unsustainable state, but the unsustainable eased year by year since 2012 .

However, the study on the ecological carrying capacity of uninhabited islands was relatively few due to the relatively small condition of uninhabited islands. An emergy evaluation was carried out to assess the carrying capacity of a small, uninhabited island (Woosedo) off the southwestern coast of Korea, and the result is that the emergy contribution of the marine ecosystem of the island was the major source of support in determining the level of carrying capacity of the island ${ }^{[8]}$. Construction of evaluation index system of ecological carrying capacity of uninhabited islands, which index data was adjusted by the social differences of different regions of the island, was establish from environmental pollution capacity, resource supply capacity and human support capability by Tu and Yang (2014) [9]. But it does not have an example to verify the feasibility of the model.

The concept and model on ecological footprint have been widely used. Uninhabited island with a small area can not provide sufficient capacity of freshwater resources, land resources, food, electricity and waste disposal capacity. Therefore, the study on the ecological carrying capacity of uninhabited islands was very few, especially the tourism carrying capacity . The calculation model of tourism carrying capacity of uninhabited islands is constructed by improved the ecological footprint model in the light of current situation and planning of uninhabited islands in Qinzhou. Taking the Seventy-two Paths as an example, the tourism ecological carrying capacity of the uninhabited island was calculated and analyzed. This provides reference to the development of uninhabited islands in the area. Mean while, it enriched the theory and application of ecological carrying capacity.

\section{Materials and Methods}

\subsection{Study Area}

Seventy-two Paths are located in the northwest of Qinzhou development zone of Guangxi Province, which is about $20 \mathrm{~km}$ away from Qinzhou City. Arounding $2 \mathrm{~km}^{2}$ of beach, there are 98 uninhabited islands, with a total area of $4.16 \mathrm{~km}^{2}$, and the total length of the coastline is $79.6 \mathrm{~km}^{[10]}$. The island region of the whole slope, and steep slope areas around the island with more than $30 \%$ of the basic. Island soil is mainly red soil, and soil parent material is sand shale; soil acidity, with $\mathrm{pH}$ value is about 4.5 . The original vegetation was destroyed, and the coverage is about $70 \%$.

2.2 Construction of Consumption Model of TEF of Uninhabited Island The calculation of TEF is usually composed of 6 parts, such as the restaurant, accommodation, traffic, entertainment, sightseeing and shopping.

\subsubsection{TEF of restaurant}

Measure of TEF of restaurant contains 3 parts: Firstly, to provide visitors to food and beverage service catering facilities area; Secondly, biological 
of tourist food consumption production area (including cultivated land, forest land, grassland, water area); finally, the energy consumption of fossil energy sources consumption area. In order to overcome the difficulties in obtaining the food consumption and energy consumption data onto tourists, it could be assumed that the amount of food consumption, energy consumption were the same as that of the locals, which could be obtained from the local statistical yearbook. The model is,

$$
T E F_{1}=\sum S+\sum_{i=1}^{n} \frac{N \times D \times C_{i}}{P_{i}}+\sum_{j=1}^{\mathrm{m}} \frac{N \times D \times E_{i}}{\mathrm{r}_{i}}
$$

Where $\mathrm{S}$ is the construction lands area of all kinds of social catering facilities; $\mathrm{N}$ is the number of tourists; $\mathrm{D}$ is the average number of travel days; $\mathrm{C}_{\mathrm{i}}$ is the daily consumption of tourists per capita consumption of $i$ kinds of food; Pi is the annual average productivity of biologically productive land corresponding to i species; $E_{j}$ is a daily consumption of $j$ energy consumption average per visitor; $r_{j}$ is average calorific value of production land area of unit fossil fuel of $j$ kinds of energy.

\subsubsection{TEF of accommodation}

It includes 2 parts: first, area of hotels, resorts, guest houses and hotels to provide accommodation of visitors; then, energy consumption of the corresponding service of heating, refrigeration, air conditioning, lighting, cleaning, TV, Internet, and so on, which provided by hotel during tourist residence. The model is,

$$
T E F_{2}=\sum_{i=1}^{n}\left(N_{\mathrm{i}} \times S_{\mathrm{i}}\right)+\sum_{i=1}^{\mathrm{n}} \frac{N_{i} \times K_{i} \times C_{i}}{\mathrm{r}}
$$

Where $\mathrm{N}_{\mathrm{i}}$ is the number of rooms of $\mathrm{i}$ hotel; $\mathrm{S}_{\mathrm{i}}$ is the average area per room of $i$ Hotel; $\mathrm{K}_{i}$ is the annual average usage rate of $i$ hotel; $\mathrm{C}_{i}$ is the amount of energy consumed in each room of $i$ hotel; $r$ is production land area of the average calorific value of unit of fossil fuel.

\subsubsection{TEF of traffic}

The calculation of TEF of traffic includes 2 aspects: (1) the construction lands area of the tourism transportation facilities; (2) Travel and transportation energy consumption. The model is,

$$
T E F_{3}=\sum_{i=1}^{n} S_{\mathrm{i}}+\sum_{\mathrm{j}=1}^{\mathrm{m}} \frac{N_{j} \times D_{j} \times C_{j}}{\mathrm{r}}
$$

Where $S_{i}$ is the area of the $i$ type of traffic facilities; $R_{i}$ is the use rate of the $i$ kind of traffic facilities, $\mathrm{N}_{\mathrm{j}}$ is the number of visitors to choose the $\mathrm{j}$ type of transport; $D_{j}$ is the average travel distance of the $j$ kinds of traffic tools; $C_{j}$ is the per distance energy consumption of the $\mathrm{j}$ species.

\subsubsection{TEF of entertainment}

It includes, (1) construction sites for visitors to provide leisure and recreational facilities, (2) energy consumption of operation. The model is,

$$
T E F_{4}=\sum_{i=1}^{n} S_{\mathrm{i}}+\sum_{\mathrm{j}=1}^{\mathrm{m}} \frac{K_{j} \times C_{j}}{\mathrm{r}}
$$

Where $S_{i}$ is the construction lands area of the i type of recreation facilities; $\mathrm{K}_{\mathrm{i}}$ is the average use rate of the $i$ kind of entertainment and leisure; $\mathrm{C}_{j}$ is the energy consumption of the $j$ kind of entertainment.

\subsubsection{TEF of sightseeing}

It includes that the total area of all kinds of scenic tour trails, roads, viewing space construction land. The model is,

$$
T E F_{5}=\sum_{i=1}^{n} P_{\mathrm{i}}+\sum_{j=1}^{m} H_{\mathrm{i}}+\sum_{k=1}^{l} V_{\mathrm{i}}
$$

Where $P_{i}$ is the tourist trail area of the $i$ tourism scenic spots; $H_{i}$ is the area of the road to the $i$ tourist attractions; $V_{i}$ is the area of scenic spots in the $i$ scenic spots.

\subsubsection{TEF of shopping}

It includes that , (1) the area of goods point of sale; (2) the area required to be occupied by a building, a biologically productive land, and a fossil energy source of the commodity in the production, processing, transportation and sales. The model is,

$$
T E F_{6}=\sum_{i=1}^{n} S_{\mathrm{i}}+\sum_{\mathrm{j}=1}^{\mathrm{m}} \frac{N_{j} \times C_{j}}{g_{j}}
$$

Where $S_{i}$ is the construction lands area of the $i$ tourism commodity sales facilities; $\mathrm{N}_{\mathrm{i}}$ is the number of visitors to buy the $\mathrm{j}$ kinds of goods; $\mathrm{C}_{\mathrm{j}}$ is the amount of fossil energy used in the production, processing, transportation and sale of the j products; $\mathrm{G}_{\mathrm{j}}$ is the annual average productivity of the local bio productive land corresponding to the $\mathrm{j}$ goods.

\subsubsection{Total TEF}

So, the total TEF are:

$$
T E F=\sum_{i=1}^{6} T E F_{\mathrm{i}}=N \times t e f
$$

Where $\mathrm{N}$ is the number of visitors, and tef is the per capita TEF demand.

2.3 Ecological Assessment and Demand of TRF of Uninhabited Island 2.3.1 Ecological carrying capacity of uninhabited islands based on ecological footprint

The value of supply of the ecological footprint, is equal to the area of this region where could provide the biological production. Therefore, the model of ecological footprint of the uninhabited island is,

$$
E F S=\alpha \times\left[\sum_{i=1}^{6}\left(r_{\mathrm{i}} \times m_{\mathrm{i}}\right)+\sum_{j=1}^{\mathrm{n}} \frac{\left(I_{j}-E_{j}\right) \times r_{j}}{p_{j}}\right]
$$

Where mi is the area of all kinds of biologically productive land; $\mathrm{Ij}$ is the annual import volume of the item $\mathrm{j} ; \mathrm{Ej}$ is the annual export volume of the $\mathrm{j}$ consumer items; $\mathrm{Pj}$ is the world's average production capacity of the category $j$ consumer goods; $r j$ is a balanced factor in the production of $j$ bio productive land. According to the report on the World Commission on environment and development, at least $12 \%$ of the land area should be set aside to protect the biodiversity. That is to say, $\alpha$ is 0.88 .

\subsubsection{Ecological deficit}

When the ecological footprint is less than the ecological carrying capacity, ecological deficit appeared, and its value is equal to ecological carrying capacity minus ecological footprint. When the ecological footprint is more than the ecological carrying capacity, ecological surplus appeared, and its value is equal to ecological carrying capacity minus ecological footprint. The ecological deficit indicates that the human load in the area were beyond the ecological capacity, and the region needs to import from outside the area lack of resources to balance the ecological footprint to meet the existing population of life under the level of consumer demands.

\subsection{Data sources}

The main source of data are,

(1) the statistical yearbook of Qinzhou city;

(2) the Statistical Yearbook of Guangxi Province;

(3) overall plans of river, lake, sea and island in Qinzhou City;

(4) remote sensing data downloaded from web (http:// map.51240.com/) without copyright restrictions.

\section{Results}

\subsection{Ecological Supply}

The total supply of the ecological footprint of Seventy-two Paths were showed in Table 1.

\begin{tabular}{ccccc}
\multicolumn{5}{c}{ Table 1. The total ecological footprint supply of Seventy-two Paths } \\
\hline Land use type & $\begin{array}{c}\text { Total } \\
\text { area (ha) }\end{array}$ & $\begin{array}{c}\text { Equilibrium } \\
\text { factor }\end{array}$ & $\begin{array}{c}\text { Yield } \\
\text { factor }\end{array}$ & $\begin{array}{c}\text { Equilibrium } \\
\text { area(ha) }\end{array}$ \\
\hline Cultivated land & 0 & 2.8 & 1.65 & 0.00 \\
Woodland & 173.17 & 1.1 & 0.91 & 173.34 \\
Grassland & 115.45 & 0.5 & 0.19 & 10.97 \\
Ocean, water & 600 & 0.2 & 1 & 120.00 \\
Fossil energy & 0 & 1.1 & 0 & 0.00 \\
sources & 0 & & &
\end{tabular}




\begin{tabular}{lllll}
\hline \multicolumn{1}{c}{ Construction land } & 127.32 & 2.8 & 1.66 & 591.78 \\
$\quad$ Total & & & & 896.09 \\
$\begin{array}{l}\text { Remove } \\
\text { biodiversity }\end{array}$ & & & & \\
conservation area & & & & 788.56 \\
\hline
\end{tabular}

\subsection{TEF}

\section{(1) TEF of restaurant}

As the difficulties in obtaining the food consumption and energy consumption data of tourists, it could be assumed that the amount of food consumption, energy consumption were the same as that of the Guangxi Province. According to the global food annual average ecological productivity and land type, land area of the world production unit of fossil fuels and average to heat conversion coefficient, and Guangxi statistical yearbook, the per capita TEF could draw $3.50 \times 10^{-3}$ ha. One million people are assumed every year in planning, that is, the need for 3500 ha.

(2) TEF of accommodation

According to the plan, the high-end Resort Hotel lands 33.52 ha, Resort Land 45.86 ha. Energy consumption of residential facilities is electricity, and the global average footprint of $1000 \mathrm{GJ} / \mathrm{ha}$. Accommodation of the construction area of 79.38 ha, energy consumption footprint is 426.83 ha, and the total tourism accommodation ecological footprint is 506.21 ha.

(3) TEF of traffic

Near from the coast, multiple bridges are planned to build which connected with the mainland. Visitors can directly from the land adjacent to the island, so the TEF of traffic mainly considering the internal and uninhabited island. According to the plan, the aere of road is $29.41 \mathrm{ha}$, the energy consumption of fossil energy to the total ecological footprint is 87.28 ha, and the total TEF of traffic are 116.69 ha.

\section{(4) TEF of entertainment}

According to the plan, the main entertainment field in island is the international cruise terminal, with the area is $3.10 \mathrm{ha}$. There is no clear other recreational facilities in the planning, so the other part was ignored.

\section{(5) TEF of sightseeing}

As the development mode of global tourism, apart from the road, building and facilities with the total areas of $127.32 \mathrm{ha}$, the left is for recreational use, namely the viewing space area is 288.62 ha. Plus the area of way 29.41 ha, the TEF of sightseeing is 318.03 ha.

\section{(6) TEF of shopping}

Since tourists shopping were not to be forecasted at the planning, per capita TEF of shopping in Nanao Island was referenced, that is, $8.75 \times 10^{-4}$ ha ${ }^{[11]}$. One million people are expected to travel annually in the planning, that is, 875 ha are needed.

\section{(7) TEF}

In conclusion, according to the plan, the TEF in Seventy-two Paths is 5319.03 ha. Without TEF of the tourists to here, tourism waste consumption of energy, the calculation result is less than the actually. The impact on tourism activities was underestimated on the ecosystem.

\subsection{Evaluation on Tourism Carrying Capacity of Uninhabited Island}

Based on the previous calculation, the sum of the TEF of the Seventy-two Paths is 5319.03 ha, and the ecological supply is only 788.56 ha. The ecological deficit is $4530.47 \mathrm{ha}$, and the ecological deficit is 5.75 times of the local ecological footprint. So, the TEF of the Seventy-two Paths is more than the ecological capacity seriously after the construction is completed.

\section{Discussion}

There are many studies on TEF of residents island because of the large area, which similarly with the mainland $[4,8,11]$. From environmental pollution capacity, resources supply capacity and human support capability, Tu and Yang (2014) [9] established construction of evaluation index system of ecological carrying capacity of uninhabited islands, which index data was adjusted by the social differences in different regions of the island. Unfortunately, no example was to be verified the feasibility of the model.

\section{Conclusion}

On the basis of the study of the TEF of large island, the result is more practical with some assumptions was fixed. The result showed that the
TEF of restaurant, accommodation, traffic, entertainment, sightseeing and shopping in Seventy-two Paths is 3500 ha, 506.21 ha, 116.69 ha, 3.10 ha, 318.03 ha and 875 ha separately. The total TEF are 5319.03 ha while the ecological supply is $788.56 \mathrm{ha}$. The ecological deficit is $4530.47 \mathrm{ha}$, which is 5.75 times of the local ecological footprint. The important influence of tourism development on the local ecological environment could not be ignored. Compare with the model of Wang et al [12], four subsystems, such as accommodation, traffic, entertainment and shopping , of the model to be improved and perfected which could better reflect the characteristics of uninhabited island. So, the result is more true and reliable.

Because of the wide range of tourism activities and consumption, there are a lot of uncertainties in reality, such as the consumption level of tourists, environmental awareness and the number of tourist in different season. So, many aspects should be further improved, such as the model of the $\mathrm{TEF}$, the conditions setting and the parameter selection and so on. There is a certain error between the calculation result and the actual value of the TEF by the restrictions of integrity and comprehensiveness of the existing statistical data and survey data in the example of Seventy-two Paths. The total TEF are low due to the ignored of TEF of traffic and so on. The results provide reference to the development of uninhabited islands in South of China. Mean while, it enriched the theory and application of ecological carrying capacity.

\section{Acknowledgements}

Thanks to the following funds, Research Center of Beibu Gulf Marine Culture Foundation(2015BMCC04), Guangxi Natural Science Foundation (2015GXNSFAA139101), Guangxi Key Research \& Development Program (GXS-AB16380164).

\section{References}

[1] W.E. Rees. "Ecological footprints and appropriated carrying capacity: what urban economics leaves out", Environment \& Urbanization, 4, pp. 121-130,(1992).

[2] W. Mathis, and W.E. Rees. "Our Ecological Footprint", Green Teacher,45, pp. 5-14,(1996).

[3] C. Hunter. "Sustainable Tourism and the Touristic Ecological Footprint", Environment Development \& Sustainability,4, pp.7-20,(2002).

[4] YM. Sun, J. Zhu, H.P. Huang. "Ecological footprint analysis on tourism sustainability of Meizhou Island". Ecological Science, 34,(6), pp.124129,(2015).

[5] Z.J. Yuan, F. Gao, Y. Sun, et al. "Coastal tourism resources development scale assessment Based on the ecological footprint model". marine development and management,2, pp.106-110,(2015).

[6] Y.M. Yang, J. Xu. "Research on sustainable development of Zhangjiajie tourism based on toursim ecological footprint model". Journal of Central South University of Forestry \& Technology,6, pp.107-110,(2016).

[7] J.F. Li, C.J. Nie. "Study on the sustainable development of tourism in forest parks of Guizhou Province based on the ecological footprint model".Journal of Mountain Agriculture and Biology, 35,(3), pp.53$57,(2016)$.

[8] J. Nam, W. Chang, D. Kang. "Carrying capacity of an uninhabited island off the southwestern coast of Korea". Ecological Modelling,221,17,pp.2102-2107, (2010).

[9] Z.S. Tu, S.L. Yang. "Evaluation method of ecological carrying capacity of uninhabited islands to construct". Marine development and management,10,pp.16-19, 29,(2014).

[10] Eco Tourism Research Institute of Guangxi University. "Overall planning of river, lake, sea and island in Qinzhou City",pp.1-78,(2013).

[11] X.Y. Lin. "Study on the development of island eco tourism based on Ecological Footprint -- a case study of Nanao Island in Guangdong Province". Xiamen University,pp.42,(2013).

[12] J. Wang, J.X. Zhao, D.H. Liu, et al. "Island tourism carrying capacity model based on Ecological Footprint and an empirical analysis of auspicious clouds Island". In. 2010 Island sustainable development forum, pp. 128-135,(2010). 